\title{
Drummond do mundo - uma resenha de Maquinação do mundo: Drummond e a mineração, de José Miguel Wisnik
}

[ Drummond of the world - a review of "Maquinação do mundo:

Drummond e a mineração", by José Miguel Wisnik

\section{Stelio Marras ${ }^{\mathrm{I}}$}

WISNIK, José Miguel. Maquinação do mundo: Drummond e a mineração. São Paulo: Companhia das Letras, 2018.

Ligeiramente modificado para esta publicação, o presente texto foi confeccionado na oportunidade do debate com José Miguel Wisnik no Instituto de Estudos Brasileiros (IEB/USP). Mantenho Wisnik como interlocutor.

RESUMO-Destaca-se aqui o caráter poluído de Drummond no mundo existencial-material da máquina capitalista que coleta e emaranha em sua prática toda sorte de humanos e não humanos. Tal reflexão tornou-se possível pelo reencantamento de Drummond por Wisnik. Daí derivam questões sobre como enunciar e repor a crítica à sociedade mercadológica a partir do poluído, implicado, vinculado. . PALAVRAS-CHAVE - Carlos Drummond de Andrade; José Miguel Wisnik; mineração. - ABSTRACT · In this review, I aim to stress some of the features of Drummond's oeuvres directly derived from his own material existence in a capitalist engineered world. A machinery that encompasses both humans and non-humans. Such proposal was born out of Wisnik's new interpretation of the abovementioned author. Thus, I try to highlight the importance of market society in order to better understand Drummond as someone imbedded in an entangled and polluted reality. · KEYWORDS · Carlos Drummond de Andrade; José Miguel Wisnik; mining

Recebido em I5 de maio de 2019

Aprovado em 20 de maio de 2019

MARRAS, Stelio. Drummond do mundo - uma resenha de Maquinação do mundo: Drummond e a mineração, de José Miguel Wisnik. Revista do Instituto de Estudos Brasileiros, Brasil, n. 73, p. 268-274, ago. 20I9.

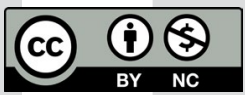

DOI: http://dx.doi.org/Io.II6o6/issn.23I6-90IX.voi73p268-274

I Universidade de São Paulo (USP, São Paulo, SP, Brasil). 
Dirijo-me a Wisnik para logo dizer que este seu livro é, para mim, e por muitas razões, um dos mais luminosos do que conheço no pensamento brasileiro da história recente. Mineiro que sou, lá de umas montanhas no contraforte da Mantiqueira, terra mineral de águas sulfurosas e muita bauxita (além de outros minérios), a mim me toca profundamente este seu trabalho de, digamos, reencantar Drummond, de fazer com que, na poesia dele, montanha, pedra, mineral, mundo falem e testemunhem seu destino que se dobra sobre o nosso - pessoas e coisas particularmente entrelaçadas na modernidade. O meu ponto aqui diz respeito a como colocar, de maneiras as mais realistas e justas, esse "destino mineral" que a todos nos concerne - a todos nós, mineiros ou não (porque somos todos minerais, em vários sentidos), todos a um só tempo engenheiros e engenhocas desse sistema de produção e consumo de bens da Grande Máquina capitalista que agora se defronta com uma ferocidade inédita de suas consequências.

Também posso, afetado pelo livro, enunciar o problema, que tanto me obseda e exaspera, com as seguintes perguntas: o que fazer diante do mundo que já não é vasto, que mais e mais se mostra finito? O que pensar do mundo no fim do mundo? Como pensar com esse mundo tornado tão ecologicamente vulnerável pelos terríveis impactos de nossas atividades econômicas que tornam a nós todos, de revés, também tão vulneráveis? Quais alternativas de pensamento e ação podemos imaginar/criar/ cultivar coletivamente a partir dessa vulnerabilidade, a partir do precário e frágil, do poluído e contaminado, do interdependente e emaranhado? Como agora saber viver e saber morrer a partir do impuro, da não exterioridade nossa em relação ao mundo, a suas máquinas e maquinações? Como entreviver e entremorrer nas ruínas e no mundo que emerge como "feral"? ? Como resistir e recomeçar no fim?

Penso que esse seu trabalho de reencantar Drummond responde aos constrangimentos ecológico-ambientais contemporâneos - a essa crise que não vai passar, como bem diz a filósofa da ciência Isabelle Stengers (20I5). É então o mundo em ruínas - essa forçante, por assim dizer - fazendo com que você revolva esse tema em Drummond e nos mostre que, afinal, já não é vasto o mundo devastado

2 Sobre a vida nas ruínas do capitalismo e o conceito de "feral”, cf. Anna Tsing (20I5; 20I9). Noto que não é menos feral o minério ecologicamente animado pelo capitalismo predatório. E que tirar poesia da pedra, esta que, retirada do modo como foi e é feita, é fazer poesia a partir das ruínas. Antevisão de Drummond. 
por essa máquina de existência (o capitalismo). É convite para pensar o "sentimento do mundo" com ênfase agora no mundo mesmo, mundo que sente, que responde, inclusive violentamente. Talvez mesmo dizer: nem bem o eu maior, menor ou igual ao mundo, mas eu e mundo agora se continuando um no outro, se pressupondo e variando reciprocamente, e produzindo consequências de difícil mensuração, previsibilidade, controle.

Ou ainda, no mesmo sentido, seu livro é convite para pensar na "lição de coisas" como lição que as coisas (ecologicamente animadas no Antropoceno) nos oferecem hoje. Lição da coisa-minério, da coisa-petróleo, de toda coisa-mercadoria produzida na escala alucinante e veloz da sociedade industrial, dessa sociedade que é aquela do "povo da mercadoria", no dizer preciso do Yanomami Davi Kopenawa (KOPENAWA; BRUCE, 20I5), que você, Wisnik, faz muito bem em recuperar. Lição desse mundo que, tornado coisa, responde como ser, como Gaia, "Sistema-Terra", "Planeta Simbiótico" feito de ecossistemas sensivelmente interdependentes e respondentes. Lição da pedra que agora se reinstala no caminho do progresso, do desenvolvimento ou do crescimento, descaminhando o que antes parecia de livre trânsito, avenida linear, evolutiva, desimpedida. É a pedra mineral, "pedra-enigma", que parece nos dizer: daqui não passará sem que tope com as consequências de seu avanço. É a máquina capitalista do mundo agora convertida na máquina anímica de Gaia. É pois como esfinge, claro enigma, que a pedra no meio do caminho nos induz hoje, mais que nunca, a urgentemente desacelerar a marcha, a moderar, a nos imbuir de tabus e pudores na relação com a natureza que emerge como tão perigosamente respondente. Daí, enfim, o desafio de pensar outros caminhos no meio da pedra, porque sem pedra, sem mundo, não há caminho possível (MARRAS, 20I5).

É na sua própria experiência relatada no livro, Wisnik, que se pode recolher o testemunho dessa ação recíproca que estabelecemos com o mundo: é você nos dizendo aqui, com todas as letras, dos impactos da viagem a Itabira que o fizeram matutar este seu livro. Assim sendo, não passará de vã a pergunta destinada a isolar a origem que fez nascer o livro: se em você, em Drummond ou no mundo. Para mim, é muito claro que essa origem não se localiza em entes, mas em entres - não no discreto, mas no contínuo, na circularidade. E sua atenção, Wisnik, não me parece se desenvolver senão precisamente a partir desses entrelugares, dessas mediações. Nada de espírito humano sem espírito do mundo. No mesmo sentido, nada de fato sem ficção, já que ambos se continuam. Senão melhor: a figuração do fato depende da empresa ficcional. Nada de realidade sem imaginação. Daí que você nos faça deslocar (ou, antes, permutar) do sentimento do poeta em relação ao mundo para o sentimento do mundo que povoa o poeta.

Dizendo de outra maneira, eu estou aqui me referindo a um chamado contemporâneo do mundo (que se multiplica em mundos) com seus gritos dirigidos a nossos ouvidos moucos - modernos ouvidos moucos enfeitiçados/enredados pelo capital. Mas, assim como vamos aprendendo a duras penas que a natureza não está lá fora, também a máquina capitalista não nos é exterior. Aliás, o avanço desta, que nos emaranha, faz emergir nosso emaranhamento naquela, e na sua face a mais ameaçadora. Elas duas se engendram, se comunicam, se comaquinam conosco. Sendo esse lugar o dos vínculos, eis aqui uma outra versão de minha questão, Wisnik: como pensar, enunciar, sentir, agir, resistir a partir dos vínculos, a partir do 
impuro, do poluído, contaminado, emaranhado, simbiótico? Poderíamos iluminar um Drummond poluído? Um mundano Drummond também ele ecologicamente situado na sociedade das coisas? Pois é isso também que seu livro me desperta e comunica. Drummond-no-mundo-da-mercadoria. Mas retomar as relações do poeta com o mundo sem operar a redução sociológica é tarefa que, para mim, você põe e cumpre de modo magistral no livro.

Toda essa tão entrelaçada maquinação de máquinas nada mecânicas nos envolve a todos. Quero dizer: não diz respeito apenas aos detentores do grande capital. Somos tão vítimas quanto algozes, passivos e ativos, engendramos as maquinações e somos por elas engendrados. Se o capitalismo nos transcende é porque ele é feito na nossa imanência a mais cotidiana. Eu estou convencido de que mercado, natureza, Estado, nenhuma dessas grandes figurações transcendentais se ergue, age e se mantém sem o envolvimento de cada um de nós nos mais comezinhos de nossos atos diários. Como sair dessa?

Das máquinas do mundo, e de fazer mundo, somos então todos partícipes, somos delas peça e motor, todos alinhados numa mesma "maquinaria dos dispositivos" (nesta sua tão precisa e preciosa expressão à p. 2I7): humanos e não humanos dispostos e disponíveis uns para os outros, dispositivos uns dos outros na maquinaria capitalista de mundo. É você mesmo, Wisnik, recuperando a noção de dispositivo de Agamben (e que também podemos lembrá-la em Foucault), que me faz pensar na necessidade (inclusive na argumentação aqui de seu próprio livro) de enfatizar esse caráter profundamente participativo que todos nós mantemos com os não humanos maquinados (tal o minério refinado) - todos nós, isto é, não apenas, e nem sobretudo, aqueles diversos avatares do grande capital financeiro que costumamos de imediato, não sem razão, mas não com toda a razão, denunciar como os vilões desse terrível estado de coisas em que ingressamos pelo Antropoceno, pelo Capitaloceno 3 .

Se clamo por uma ênfase dessa nossa participação na Grande Máquina capitalista, é porque, penso, grandiosas reflexões, como as suas neste livro, não podem entrar em risco, por mínimo que seja, por uma leitura que termine por delimitar, de modo simplificado, culpados e inocentes. É, em suma, enfatizar o que está latente no verso de Drummond que você deixa vazar na p. I38: "Cada um de nós tem seu pedaço no pico do Cauê". Sim, somos todos "filhos da mineração". No mesmo sentido, eu lembro, sempre lembro, aqueles versos de Drummond em "Relógio do Rosário", nos quais o poeta se situa na instância do que estou aqui chamando de poluído:

nada é de natureza assim tão casta

que não macule ou perca sua essência

ao contato furioso da existência.

Você fala, Wisnik, da "pulsão predadora e espoliadora investida nos interesses que se alimentaram e se realimentaram das jazidas de Minas Gerais” (p. I69). Sim, sem dúvida. E, contudo, eu argumento aqui, essa pulsão pulsa porque nós todos, figurados como consumidores, dependemos dos produtos dessas jazidas: nossa pulsão alimenta aquela do grande capital, não é? Pergunto: como avançar a crítica para além

3 Sobre o Capitaloceno, cf. Haraway, 2016. 
ou aquém da acusação dos grandes beneficiários do capital? Claro que eu também aponto o dedo para os "responsáveis" pelos crimes de Mariana e Brumadinho. Claro que faço coro à aplicação de punições severas, restituições de dinheiro, indenizações, multas sociais e ambientais, investimento em recuperação etc. Claro que morro de indignação com o fato de que a política da Vale, desde a sua privatização (vendida por 3 bilhões de dólares e tendo reservas de mais de Ioo bilhões), é a de distribuir cerca de $66 \%$ dos lucros líquidos, como ocorreu entre 2008 e 20I7, sendo que o próprio estatuto da empresa indica $25 \%$ de repasse obrigatório. E que os investimentos para a manutenção da operação, mesmo depois do acontecido em Mariana, foram reduzidos pela metade. Então são claras as prioridades da Vale que se tornou multinacional e grande exportadora de dividendos não taxados para fora do Brasil. Para piorar, a Vale ainda se beneficia de enormes incentivos fiscais do governo. E claro ainda que as grandes empresas e governos que compram esses minérios mundo afora são corresponsáveis por esses crimes. Mas o meu ponto, vou insistindo, é que cada um de nós que consome os minérios (e todos, sem exceção, os consumimos e deles nos beneficiamos), cada um de nós - incluindo os consumidores do minério brasileiro no exterior - deve trazer a responsabilidade para si também, porque somos também partícipes de todas as consequências sociais e naturais dessa extração.

A "feitiçaria capitalista", para falar com Phillipe Pignarre e Isabelle Stengers (2007), é esse "sistema feiticeiro sem feiticeiros". Pois então: como nos protegermos dessa feitiçaria, como desenvolver e cultivar "práticas de desenfeitiçamento" ao nos aceitarmos simbioticamente ligados a essa máquina? E como, sobretudo, fazer isso recusando a chave tão improdutiva da denúncia? Meu medo cada vez mais crescente, Wisnik, é esse de nos bastarmos na denúncia dos poucos e grandes agentes do capitalismo, nos esquecendo de nossa própria ação maquinadora: nós, os pequenos, mas muitos, agentes do capitalismo. Daí que me pergunto: a grande produção de mercadorias não depende do grande consumo delas? As grandes corporações não dependem de cada um de nossos corpos? Eu preciso simultaneamente considerar aquilo que nosso dedo aponta e o nosso dedo que aponta aquilo. Considerar, sem medo ou subterfúgios, que o capitalismo nos constitui, nos atravessa.

O ponto, para mim, é que por mais "ambientalmente correto" que seja o processo de extração (tal a de minérios e petróleo, para ficar só nisso), ainda assim são terríveis as consequências (ambientais, ecológicas, civilizacionais) dessa extração em escala e velocidade voltada ao abastecimento desenfreado da chamada sociedade do consumo. Como se sabe, essa expansão do consumo de bens-isso que muitos de nós entendemos como condição para promover maior igualdade econômica e social por via do desenvolvimento e crescimento-, essa expansão é absolutamente incompatível com o que o planeta é capaz de sustentar. Como agora nos reconhecermos profundamente atados a esse sistema sem com isso nos vermos de mãos atadas? Como criar no mais cotidiano de nossas vidas as resistências ao domínio do capitalismo a partir dele, de dentro dele?

O capitalismo, que tanto acusamos, nos é entranhado no mais fundo e superficial de nossas vidas. Não consigo me esquivar dessa evidência. Eu me indago diariamente: como renovar a crítica ao capitalismo ao nos reconhecermos envolvidos até o pescoço nele? Mas como fazer isso sem o pejo do remorso e da simples denúncia? O ferro cuja extração violenta Drummond soube tão bem criticar (como você bem nos mostra, Wisnik) 
é, contudo, o mesmo ferro dos aros dos óculos do poeta, o mesmo ferro de sua máquina de escrever. $\mathrm{O}$ ferro imprimiu cada letra que compõe as palavras de Drummond... Juro que não encontro facilidade em distinguir o metal bom do metal mau.

Mas atentar para essa nossa visceral dependência em relação aos objetosmercadorias não deve ter como efeito a paralisia da ação, da crítica, do pensamento, da resistência. Como então, repito, fazer a crítica fora do registro da culpa e da denúncia? É que a denúncia tem como efeito, no mais das vezes, localizar e fixar a responsabilidade em outrem, de modo a, por assim dizer, nos incluir fora dessa. Aprendo com Stengers que não é responsável transferir a responsabilidade aos nossos "responsáveis". Aprendo com ela que, "se a denúncia tivesse sido eficaz, o capitalismo estaria morto há muito tempo" (STENGERS, 20I7). Ou, ainda, Vinciane Despret (20I5): “denunciar a mentira pode ser uma etapa necessária, mas parar aí é se recusar a pensar”.

Para terminar, não seria preciso dizer, Wisnik, que de modo algum você se basta na denúncia. Está longe disso o principal do que você faz Drummond fazer, do que o faz dizer para nós hoje. Eu apenas quis chamar a atenção para algo talvez residual que aparece aqui ou ali em seu livro, mas que pode produzir entre leitores menos advertidos a impressão de que nós nada temos a ver com o que você chama (como, por exemplo, na p. 74) de "poderes maquinadores do mundo", ou, no mesmo sentido (p. I78), de "A 'Grande Máquina' dos poderes soberanos”. Fará sentido para você esse meu pequeno, mas sensível, incômodo?

Sou muito grato a você por me fazer sentir e pensar o que, meio de mau jeito, relatei aqui.

SOBRE O AUTOR

STELIO MARRAS é professor de Antropologia do Instituto de Estudos Brasileiros da Universidade de São Paulo (IEB/USP), membro do Centro de Estudos Ameríndios (CEstA/USP) e cocoordenador do Laboratório de Estudos Pós-Disciplinares (Lapod/USP). E-mail: smarras@usp.br https://orcid.org/0000-0002-4283-IIO7

\section{REFERÊNCIAS}

DESPRET, Vinciane. Entrevista com Isabelle Stengers e Vinciane Despret. Entrevista concedida a Oiara Bonilla e Tatiana Roque. DR, Entrevista da Vez, edição I, março de 20I5. Disponível em: <http:// revistadr.com.br/posts/entrevista-com-isabelle-stengers-e-vinciane-despret-2 >. Acesso em: abr. 2019 . HARAWAY, Donna. Antropoceno, Capitaloceno, Plantationoceno, Chthuluceno: fazendo parentes. Cli- 
maCom Cultura Científica - pesquisa, jornalismo e arte, ano 3, n. 5 ("Vulnerabilidade"), Campinas, Labjor, abril de 20I6, p. I39-I48.

KOPENAWA, Davi; ALBERT, Bruce. A queda do céu: palavras de um xamã yanomami. São Paulo: Companhia das Letras, 2015.

MARRAS, Stelio. No meio da pedra, um caminho: impactos ambientais na ecologia antropológica. Revista Florestan - Graduação em Ciências Contábeis da UFSCar, ano 2, n. 4, dezembro de 20I5, p. 25-34.

PIGNARRE, Philippe; STENGERS, Isabelle. La sorcellerie capitaliste: pratiques de désenvoûtement. Paris, La Découverte, 2007.

STENGERS, Isabelle. Entrevista com Isabelle Stengers e Vinciane Despret. Entrevista concedida a Oiara Bonilla e Tatiana Roque. DR, Entrevista da Vez, edição I, março de 20I5a. Disponível em: <http:// revistadr.com.br/posts/entrevista-com-isabelle-stengers-e-vinciane-despret-2〉. Acesso em: abr. 20I9.

STENGERS, Isabelle. No tempo das catástrofes: resistir à barbárie que se aproxima. São Paulo: Cosac Naify, $20 I 5 b$.

STENGERS, Isabelle. O preço do progresso: conversa com Isabelle Stengers. Entrevista concedida a Mathieu Rivat e Aurélien Berlan. DR, Dossiê Magia e Reprodução, Edição 4, dezembro 20I7. Disponível em: 〈http://revistadr.com.br/posts/o-preco-do-progresso-conversa-com-isabelle-stengers $>$. Acesso em: abr. 2019.

TSING, Anna. The mushroom at the end of the world: on the possibility of life in capitalist ruins. Princeton: Princeton University Press, 2015. . Viver nas ruínas: paisagens multiespécies no Antropoceno. Brasília: IEB Mil Folhas, 2019. 